\title{
Patient-reported and doctor-reported symptoms when faecal immunochemical tests are requested in primary care in the diagnosis of colorectal cancer and inflammatory bowel disease: a prospective study
}

Cecilia Högberg $^{1 *} \mathbb{D}$, Pontus Karling², Jörgen Rutegård ${ }^{3}$ and Mikael Lilja ${ }^{1}$

\begin{abstract}
Background: Rectal bleeding and a change in bowel habits are considered to be alarm symptoms for colorectal cancer and they are also common symptoms for inflammatory bowel disease. However, most patients with these symptoms do not have any of these diseases. Faecal immunochemical tests (FITs) for haemoglobin are used as triage tests in Sweden and other countries but little is known about the symptoms patients have when FITs are requested.

Objective: Firstly, to determine patients' symptoms when FITs are used as triage tests in primary care and whether doctors record the symptoms that patients report, and secondly to evaluate the association between symptoms, FIT results and possible prediction of colorectal cancer or inflammatory bowel disease.
\end{abstract}

Methods and materials: This prospective study included 364 consecutive patients for whom primary care doctors requested a FIT. Questionnaires including gastrointestinal symptoms were completed by patients and doctors.

Results: Concordance between symptoms reported from patients and doctors was low. Rectal bleeding was recorded by $43.5 \%$ of patients versus $25.6 \%$ of doctors, FITs were negative in 58.3 and $52.7 \%$ of these cases respectively. The positive predictive value (PPV) of rectal bleeding recorded by patients for colorectal cancer or inflammatory bowel disease was 9.9\% (95\% confidence interval [CI] 5.2-14.7); for rectal bleeding combined with a FIT the PPV was 22.6\% (95\% Cl 12.2-33.0) and the negative predictive value (NPV) was 98.9\% (95\% Cl 96.7-100). For patient-recorded change in bowel habits the PPV was 6.1\% (95\% Cl 2.4-9.8); for change in bowel habits combined with a FIT the PPV was $18.2 \%$ (95\% Cl 9.1-30.9) and the NPV 100\% (95\% Cl 90.3-100).

(Continued on next page)

\footnotetext{
* Correspondence: cecilia.hogberg@umu.se

${ }^{1}$ Department of Public Health and Clinical Medicine, Unit of Research,

Education and Development - Östersund, Östersund Hospital, Umeå University, Umeå, Sweden

Full list of author information is available at the end of the article
}

(C) The Author(s). 2020 Open Access This article is licensed under a Creative Commons Attribution 4.0 International License, which permits use, sharing, adaptation, distribution and reproduction in any medium or format, as long as you give appropriate credit to the original author(s) and the source, provide a link to the Creative Commons licence, and indicate if changes were made. The images or other third party material in this article are included in the article's Creative Commons licence, unless indicated otherwise in a credit line to the material. If material is not included in the article's Creative Commons licence and your intended use is not permitted by statutory regulation or exceeds the permitted use, you will need to obtain permission directly from the copyright holder. To view a copy of this licence, visit http://creativecommons.org/licenses/by/4.0/. The Creative Commons Public Domain Dedication waiver (http://creativecommons.org/publicdomain/zero/1.0/) applies to the data made available in this article, unless otherwise stated in a credit line to the data. 
(Continued from previous page)

Conclusions: Doctors should be aware that, during consultations, they do not record all symptoms experienced by patients. FITs requested in primary care, when found positive, may potentially be of help in prioritising referrals, also when patients present with rectal bleeding or change in bowel habits.

Keywords: Colorectal neoplasms, Faecal immunochemical test, Gastrointestinal symptoms, Occult blood, Primary care, Rectal bleeding

\section{Background}

Colorectal cancer (CRC) is the third most common cancer worldwide [1]. The cumulative life prevalence is approximately 5\% [2]. Early stage CRC is often asymptomatic, and when symptoms develop it is of importance to determine a diagnosis without delay, as longer diagnostic intervals may result in higher mortality [3].

Rectal bleeding, change in bowel habits and weight loss are considered to be alarm symptoms for CRC, and guidelines on suspected CRC recommend that patients who experience these symptoms be referred to secondary care [4-6]. However, these symptoms are common amongst the general public and in patients consulting primary care $[7,8]$, and the majority of these patients do not have significant colorectal disease $[9,10]$. Additionally, many of the patients that have CRC present other symptoms than rectal bleeding, change in bowel habits or weight loss when they consult primary care [11]. Furthermore, CRC and inflammatory bowel disease (IBD) can present with the same symptoms $[9,12]$. It can be a challenge for primary care doctors to decide which patients to refer to secondary care for further investigation.

Faecal immunochemical tests (FITs) for haemoglobin can be used as triage tests [4, 6, 13-18]. In Sweden, qualitative point of care (POC) dip-stick FITs are in common use in primary care. We have previously shown that the combination of a POC FIT and haemoglobin analysis is a sensitive method for detecting CRC in symptomatic patients in primary care [12]. Therefore, understanding how doctors have interpreted and recorded patients' symptoms when FITs are requested has importance for the detection of CRC. To our knowledge this has not previously been studied.

The primary aim of the study was to determine the characteristics and extent of patients' symptoms when FITs are used as triage tests in primary care, and to determine whether doctors recorded the symptoms that patients reported, and the secondary aim was to evaluate in these patients the association between the symptoms, FIT results and possible prediction of CRC or IBD.

\section{Methods}

We conducted a prospective study in the region of Jämtland Härjedalen in Sweden, including four primary care centres covering around 29.000 people.
Between 30 January 2013 and 31 May 2014, consecutive patients aged 20 years and older for whom a doctor requested a FIT were invited to take part in the study. Trained nurses informed eligible patients, distributed patients' information sheets with thorough information about the purpose of the study and ensured that each patient was able to read this (Additional file 1). Questionnaires and tests were distributed to those consenting to participate. The nurses instructed the patients on how to collect the faecal samples. The patients' consents were verbal, and only patients that returned their questionnaires were included in the study. This procedure, including the written information and the verbal consent, was approved by the Regional Ethical Review Board Umeå. At the time of the study there were no Swedish guidelines regarding suspected CRC, no earlier or ongoing screening for $\mathrm{CRC}$ in the region and none of the patients had participated in screening programmes. Further details on methods, power calculation and participants have been published previously [12]. The study was performed according to the STARD guidelines [19].

\section{Questionnaires}

\section{Patients' questionnaires}

Binary variables (yes/no) were used for questions about alarm symptoms during the previous year. These questions included rectal bleeding in toilet, rectal bleeding on toilet paper, black faeces, change in bowel habits and weight loss. To explore other common gastrointestinal symptoms, we used the validated Gastrointestinal Symptom Rating Scale for irritable bowel syndrome (GSRSIBS) with thirteen questions, and also five questions from the original GSRS questionnaire [20, 21]. The questions in the GSRS questionnaires use a 7-point Likert scale and ask about symptoms perceived during the previous week. The answers were grouped into seven clusters: abdominal pain, constipation, diarrhoea, reflux symptoms, bloating, satiety and dyspepsia. In each cluster the result of the question with the highest numerical value was recorded. The results from the two questions about incomplete evacuation and urgency were treated separately. The patients' questionnaire is presented in Additional file 2. 


\section{Doctors' questionnaires}

After the consultation, the doctor was asked to complete a questionnaire including symptoms and findings that the doctor had noted during the consultation. Four questions corresponded to the patients' questions about rectal bleeding, black faeces, change in bowel habits and weight loss, six questions corresponded to the symptom clusters and questions of the GSRS-IBS, and two questions to examination findings. The questions could be answered with "yes", "no" or "unknown/not examined". The doctors' questionnaire is presented in Additional file 3.

\section{Faecal immunochemical tests (FITs)}

The FIT used was the qualitative test Actim Fecal Blood (Oy Medix Biochemica Ab, Finland). This visually interpreted, immunochromatographic dip-stick test was the faecal occult blood test used at all primary care centres as well as the central laboratory at the regional hospital in Jämtland Härjedalen at the time of the study. The laboratories at the primary care centres are all supervised by the Department of Laboratory Medicine at Östersund Hospital (the regional hospital). Each test stick had a built-in control line for quality control of the chromatographic process. The collection tube had a sampling stick attached to the cap which collected an expected mass of 10-20 mg faeces in $10 \mathrm{ml}$ buffer solution [22]. Patients were instructed by experienced laboratory nurses to twist the stick randomly in several different places in the faeces, to store the samples in a refrigerator and to deliver them as soon as possible to the primary care centre. The FITs were analysed on arrival at each primary care centre by experienced laboratory staff, who had no access to clinical information. According to the manufacturer at the time of the study, the cut-off value for a positive result was $50 \mathrm{ng}$ haemoglobin $/ \mathrm{ml}$ of faecal solution corresponding to 25-50 $\mathrm{mg}$ haemoglobin/g faeces and test results remained positive up to $500 \mathrm{ng}$ haemoglobin $/ \mathrm{ml}$ [22]. The range given of the cut-off value was due to the possible variations in the weight of the collected faeces. Each FIT consisted of three samples from consecutive bowel movements and a result was considered positive when at least one of the samples showed a positive reading. It was in the region customary to request three samples for one FIT.

\section{Significant colorectal disease}

Doctors were instructed to refer patients with positive FITs for a colonoscopy and otherwise to follow their usual procedures. Significant colorectal disease was defined as $\mathrm{CRC}$, adenomas with high-grade dysplasia (HGD), adenomas $\geq 1 \mathrm{~cm}$ with low-grade dysplasia (LGD), or IBD. Such adenomas were recorded as they can be precursors to CRC. The FIT results were available to the endoscopists. All patients were followed for 2 years. Data regarding colonoscopies, sigmoidoscopies, CT colonographies, double contrast barium enemas and diagnoses was retrieved from patients' electronic medical records that were shared across the primary care centres and all hospital departments. If no CRC or IBD was diagnosed during the two-year follow-up, the patients were considered as not having these diseases.

\section{Statistics}

We used SPSS version 24 for statistical analyses (IBM, Armonk, NY, USA). Comparisons were made using Pearson's Chi-square test with Yate's continuity correction or Fisher's exact test, as appropriate. A $p$-value of $<$ 0.05 was considered significant. As not all patients were investigated with bowel imaging, positive predictive values (PPV) and negative predictive values (NPV) with 95\% confidence intervals (CI) for FITs and rectal bleeding were calculated only for the diagnoses of CRC and IBD. The relationship between CRC and IBD, and reported symptoms together with FIT results was explored using Cox regression analysis. The presence of CRC or IBD was used as a dependent variable. Sex and variables with a $p<0.10$ were included in the analysis as independent dichotomised variables and age was included as a continuous variable. Patient-reported and doctorreported symptoms were calculated separately. The result of the Cox regression analysis is presented as hazard ratio (HR) with $95 \% \mathrm{CI}$. Due to the exploring nature of the study we did not correct for multiple testing.

\section{Results}

Of 510 eligible patients 375 returned the questionnaire. Six of these moved from the region and five died of other causes during the follow-up. 364 patients $(64.3 \%$ women, median age 64 years) were included in the analysis (Fig. 1). In 356 of these cases, the doctor's questionnaire was returned. In 135 cases the patient declined to participate or did not return the questionnaire $(65.8 \%$ women, median age 65 years).

The results of the answers are presented in Table 1. The most common symptom reported by patients was bloating, followed by abdominal pain. Defecation abnormalities were also frequently reported. The symptom most frequently recorded by doctors was abdominal pain, however in general the doctors recorded fewer symptoms than the patients. Almost half of the patients (43.5\%) reported rectal bleeding, while this symptom was recorded by $25.6 \%$ of the doctors.

Agreeing positive answers from the patient and the doctor, to the four questions answered with yes/no by the patient and yes/no/unknown by the doctor, varied from $22.9 \%$ (black faeces) to $60.9 \%$ (change of bowel 


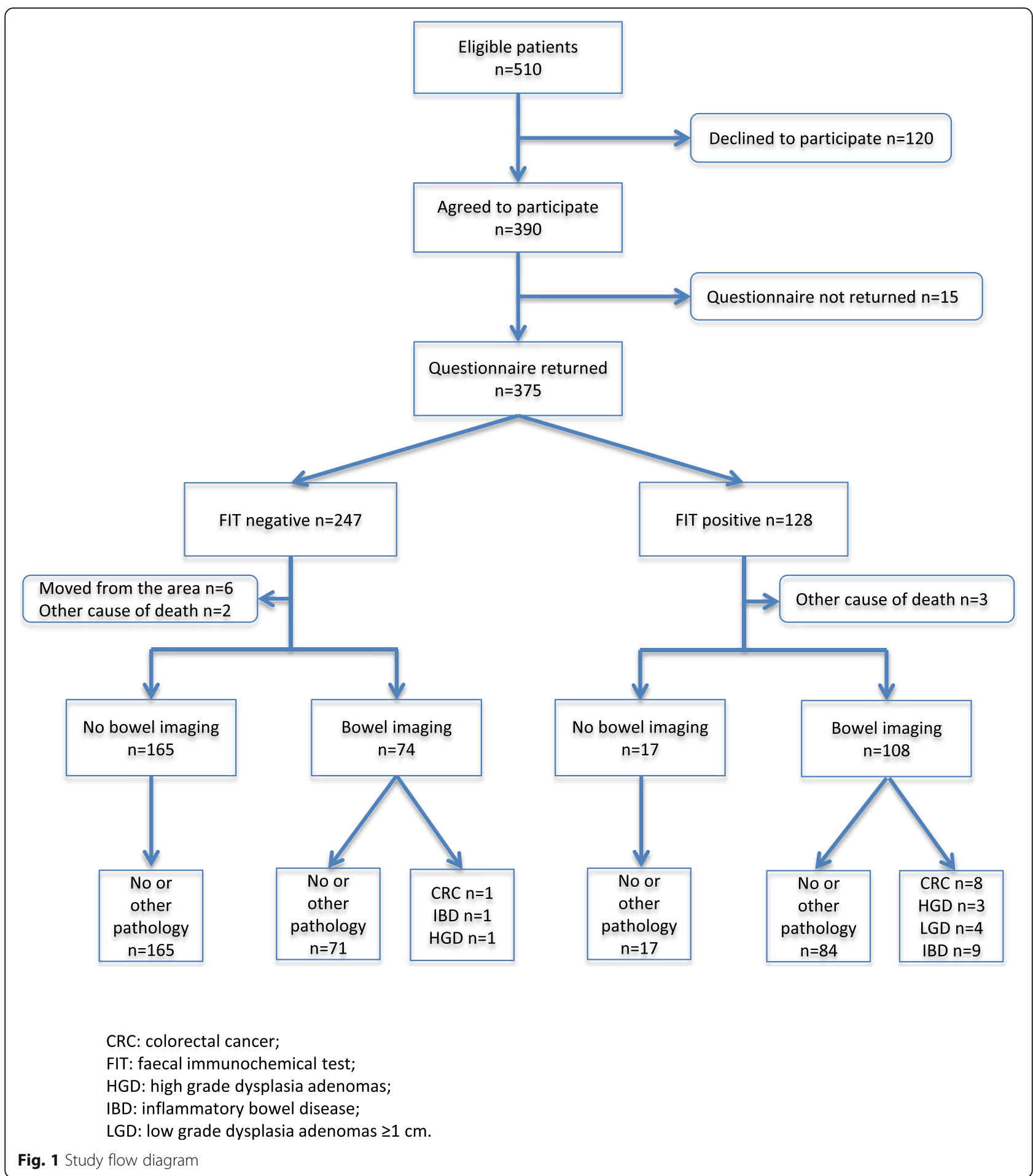

habits) (Table 2). In general, if a patient rated a symptom as more severe, the doctor more often reported the same symptom. For questions with grading of symptoms and where patients had noted "moderate discomfort" or worse, the highest percentage of agreeing positive answers was for abdominal pain $(72,2 \%)$.
All patients included in the study also provided faecal samples for the FITs. When patients recorded rectal bleeding, FITs were negative in $58.3 \%$ of cases; when doctors recorded rectal bleeding, FITs were negative in $52.7 \%$ (Table 3). Two of the patients that recorded rectal bleeding and had negative FITs had significant colorectal 
Table 1 Symptoms and findings reported by patients and doctors respectively, when a faecal immunochemical test (FIT) was requested in primary care

\begin{tabular}{|c|c|c|c|c|c|}
\hline \multirow[b]{2}{*}{ Symptoms } & \multirow[b]{2}{*}{$\mathrm{N}$} & \multirow{2}{*}{$\begin{array}{l}\text { Patients } \\
\text { Mild discomfort or more (\%) }\end{array}$} & \multicolumn{3}{|c|}{ Doctors $N=356$} \\
\hline & & & Yes (\%) & No (\%) & Unknown (\%, \\
\hline Abdominal pain ${ }^{a}$ & 364 & $266(73.1)$ & $201(56.5)$ & $149(41.9)$ & $6(1.7)$ \\
\hline Diarrhoea $^{a}$ & 361 & $212(58.7)$ & $151(42.4)$ & $191(53.7)$ & $14(3.9)$ \\
\hline Urgency $^{a}$ & 360 & $186(51.7)$ & $72(20.2)$ & $249(69.9)$ & $35(9.8)$ \\
\hline Constipation $^{a}$ & 359 & $189(52.6)$ & $94(26.4)$ & $246(69.1)$ & $16(4.5)$ \\
\hline Incomplete evacuation ${ }^{a}$ & 361 & $198(54.8)$ & $55(15.4)$ & $253(71.1)$ & $48(13.5)$ \\
\hline Reflux symptoms ${ }^{\mathrm{a}}$ & 362 & $122(33.7)$ & $44(12.4)$ & $262(73.6)$ & $50(14.0)$ \\
\hline Bloating $^{a}$ & 362 & $303(83.7)$ & & & \\
\hline Dyspepsia $^{a}$ & 363 & $202(55.6)$ & & & \\
\hline Satiety $^{a}$ & 361 & $168(46.5)$ & & & \\
\hline Change in bowel habits ${ }^{\mathrm{b}}$ & 342 & $164(48.0)$ & $158(44.4)$ & $188(52.8)$ & $10(2.8)$ \\
\hline Rectal bleeding ${ }^{b}$ & 347 & $151(43.5)$ & $91(25.6)$ & $245(68.8)$ & $20(5.6)$ \\
\hline Black faeces ${ }^{b}$ & 338 & 72 (21.3) & $20(5.6)$ & $317(89.0)$ & $19(5.3)$ \\
\hline Weight loss ${ }^{\mathrm{b}}$ & 343 & $65(19.0)$ & 45 (12.6) & $288(80.9)$ & $23(6.5)$ \\
\hline Anaemia ${ }^{\text {ad }}$ & & & $62(17.4)$ & $227(63.8)$ & $67(18.8)$ \\
\hline Abdominal mass ${ }^{a}$ & & & $4(1.1)$ & $320(89.9)$ & $32(9.0)$ \\
\hline One or more alarm symptom ${ }^{c}$ & 352 & $260(73.9)$ & $229(64.3)$ & & \\
\hline Two or more alarm symptoms ${ }^{c}$ & 345 & $100(29.0)$ & $58(16.3)$ & & \\
\hline Three alarm symptoms ${ }^{c}$ & 340 & $15(4.4)$ & $2(0.6)$ & & \\
\hline
\end{tabular}

auestions answered on a scale from "no discomfort" to "very severe discomfort" by patients, and with "yes", "no" or "unknown" by doctors

"Question answered with "yes" or "no" by patients and with "yes", "no" or "unknown" by doctors

"Alarm symptoms: Rectal bleeding, change in bowel habits, weight loss

${ }^{\mathrm{d}}$ As known when the FITs were requested

disease: one patient with CRC in the proximal colon recorded blood on the toilet paper, and one with a HGD adenoma recorded blood in the toilet. Both these patients had anaemia according to the hospital laboratory's definition (haemoglobin $<117 \mathrm{~g} / \mathrm{l}$ in women, $<134 \mathrm{~g} / 1$ in men). The PPV of a FIT combined with patient-reported rectal bleeding was $22.6 \%$ (95\% CI 12.2-33.0) for CRC or IBD. In patients that

Table 2 Agreeing positive answers from patient and doctor, stratified for grading of symptoms as stated by the patient

\begin{tabular}{|c|c|c|c|c|c|c|c|c|c|c|c|c|c|}
\hline \multirow[b]{3}{*}{ Symptoms } & \multirow[b]{3}{*}{$\mathrm{N}$} & \multicolumn{12}{|c|}{ Positive answers for different grading of symptoms by patients } \\
\hline & & \multicolumn{2}{|c|}{$\begin{array}{l}\text { Minor discomfort } \\
\text { or more }\end{array}$} & \multicolumn{2}{|c|}{$\begin{array}{l}\text { Mild discomfort or } \\
\text { more }\end{array}$} & \multicolumn{2}{|c|}{$\begin{array}{l}\text { Moderate } \\
\text { discomfort or } \\
\text { more }\end{array}$} & \multicolumn{2}{|c|}{$\begin{array}{l}\text { Moderately } \\
\text { severe discomfort } \\
\text { or more }\end{array}$} & \multicolumn{2}{|c|}{$\begin{array}{l}\text { Severe } \\
\text { discomfort or } \\
\text { more }\end{array}$} & \multicolumn{2}{|c|}{$\begin{array}{l}\text { Very severe } \\
\text { discomfort }\end{array}$} \\
\hline & & Patient & Both (\%) & Patient & Both (\%) & Patient & Both (\%) & Patient & Both (\%) & Patient & Both $(\%)$ & Patient & Both $(\%)$ \\
\hline Abdominal pain ${ }^{a}$ & 356 & 305 & $194(63.6)$ & 262 & $183(69.8)$ & 216 & $156(72.2)$ & 105 & $88(83.8)$ & 34 & $29(85.3)$ & 6 & $5(83.3)$ \\
\hline Diarrhoea $^{a}$ & 353 & 258 & 139 (53.9) & 208 & 124 (59.6) & 169 & $110(65.1)$ & 102 & 79 (77.5) & 52 & $46(88.5)$ & 18 & $17(94.4)$ \\
\hline Urgency $^{\mathrm{a}}$ & 352 & 227 & $66(29.1)$ & 182 & 63 (34.6) & 143 & $59(41.3)$ & 99 & $48(48.5)$ & 46 & $24(52.2)$ & 10 & $8(80.0)$ \\
\hline Constipation $^{a}$ & 351 & 243 & $86(35.4)$ & 185 & 77 (41.6) & 145 & $67(46.2)$ & 84 & $51(60.7)$ & 38 & $27(71.1)$ & 15 & $12(80.0)$ \\
\hline Incomplete evacuation ${ }^{a}$ & 353 & 259 & $52(20.1)$ & 194 & $48(24.7)$ & 160 & $41(25.6)$ & 81 & $22(27.2)$ & 36 & $13(36.1)$ & 10 & $6(60.0)$ \\
\hline Reflux symptoms ${ }^{a}$ & 354 & 175 & 39 (22.3) & 120 & $26(21.7)$ & 75 & $20(26.7)$ & 36 & $12(33.3)$ & 15 & $6(40.0)$ & 5 & $1(20.0)$ \\
\hline Change in bowel habits ${ }^{b}$ & 335 & 161 & $98(60.9)$ & & & & & & & & & & \\
\hline Rectal bleeding ${ }^{b}$ & 339 & 148 & $84(56.8)$ & & & & & & & & & & \\
\hline Black faeces $^{b}$ & 330 & 70 & $16(22.9)$ & & & & & & & & & & \\
\hline Weight loss ${ }^{\mathrm{b}}$ & 335 & 62 & $35(56.5)$ & & & & & & & & & & \\
\hline
\end{tabular}

aQuestions answered on a scale from "no discomfort" to "very severe discomfort" by patients, and with "yes", "no" or "unknown" by doctors

buestion answered with "yes" or "no" by patients and with "yes", "no" or "unknown" by doctors 


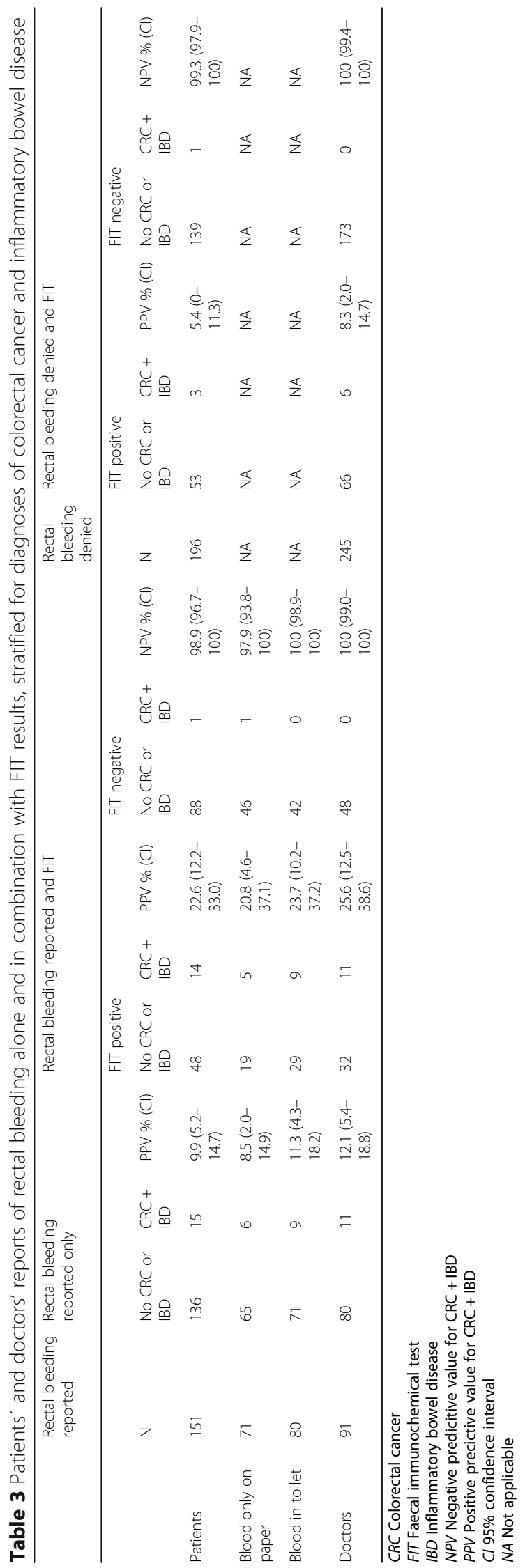




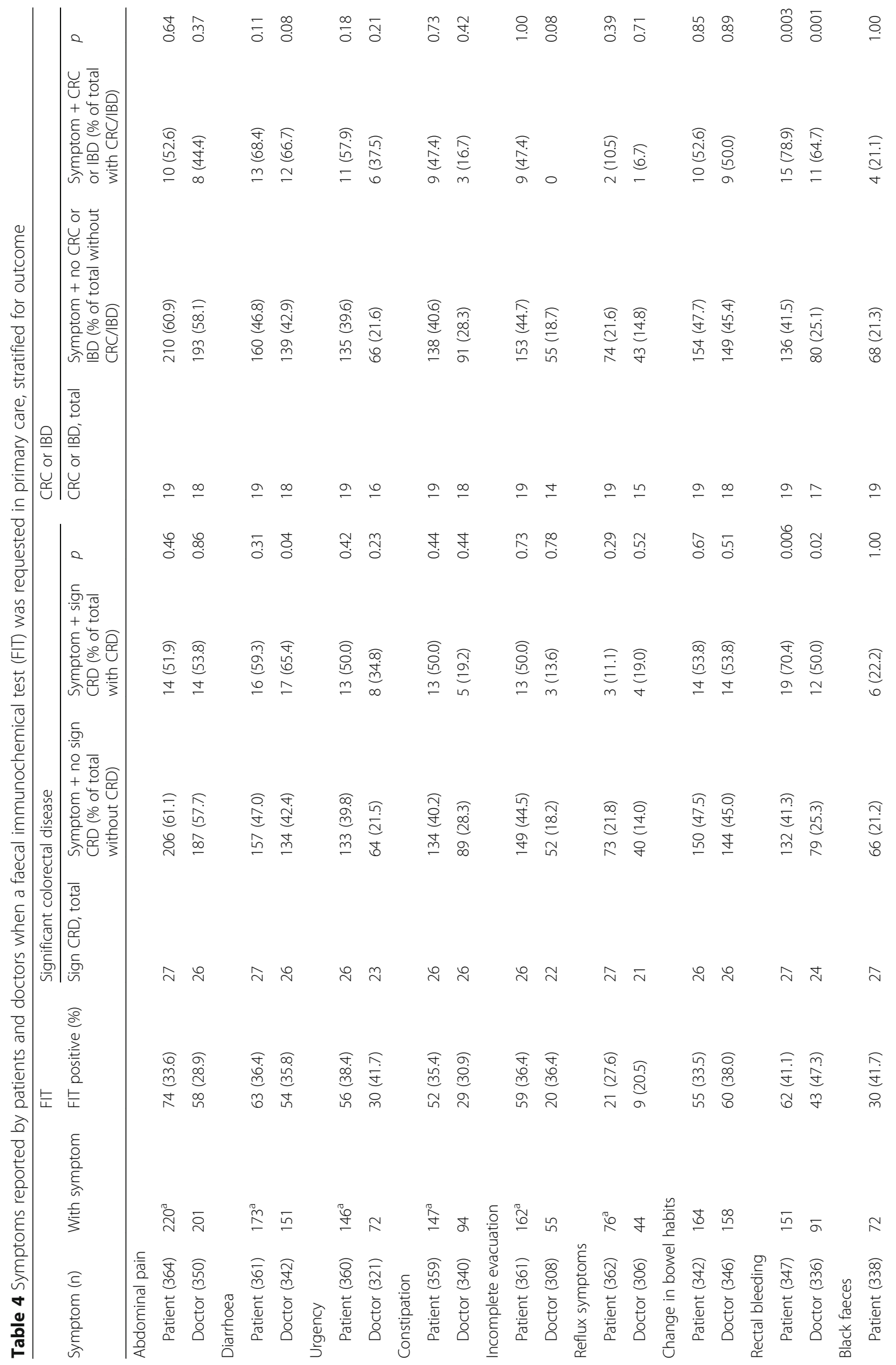




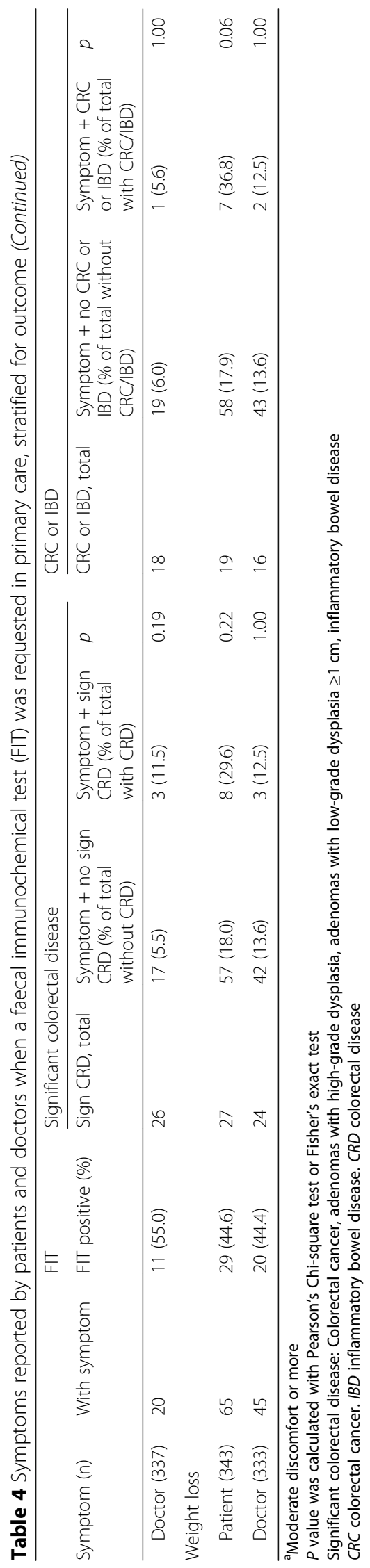


denied rectal bleeding, the FIT had a PPV of 5.4\% for CRC or IBD.

For patient-recorded change in bowel habits the PPV for CRC or IBD was $6.1 \%$ (95\% CI 2.4-9.8); for change in bowel habits combined with a FIT the PPV was $18.2 \%$ (95\% CI 9.1-30.9) and the NPV was 100\% (95\% CI 96.7-100). For patient-recorded weight loss the PPV for CRC or IBD was $10.8 \%$ (95\% CI 3.2-18.3); for weight loss combined with a FIT the PPV was $24.1 \%$ (95\% CI 10.3-43.5) and the NPV 100\% (90.3-100).

Bowel imaging was performed on 182 patients (Fig. 1). Of the 62 patients that recorded rectal bleeding and had positive FITs, $53(85.5 \%)$ were investigated (50 with colonoscopy and three with CT colonography). Of the 89 patients that recorded rectal bleeding and had negative FITs, 32 (36.0\%) were investigated (23 with colonoscopy, one with CT colonography, and eight with a barium enema). In addition, rigid rectoscopy was performed on eleven patients that recorded rectal bleeding (five with positive FITs and six with negative FITs). In total, significant colorectal disease was diagnosed in 27 patients. There were no adverse events during bowel imaging.

Table 4 shows symptoms recorded by patients and doctors stratified for outcome. CRC and IBD were related to rectal bleeding recorded by patients and by doctors.

Using Cox regression analysis, we related reported symptoms and the FIT results to the diagnoses of CRC/ IBD (dependent factor). In the Cox regression analysis of patient-reported symptoms a positive FIT (HR 15.8; CI 3.65-69.2), female sex (HR 3.28; 95\% CI 1.05-10.3), reported rectal bleeding (HR 7.47; CI 2.16-25.8), reported diarrhoea (HR 2.78; CI 1.03-7.52) and reported weight loss (HR 3.68; CI 1.35-10.1) was significantly associated to $\mathrm{CRC} / \mathrm{IBD}$. In the analysis of doctor-reported symptoms only a positive FIT (HR 15.8; CI 3.59-70.1) and reported rectal bleeding (HR 3.03; CI 1.06-8.65) was associated to CRC/IBD.

\section{Discussion}

Abdominal pain was the most common symptom reported by patients as well as by doctors. Diarrhoea and change in bowel habits were also frequently reported. Rectal bleeding was recorded by $43.5 \%$ of the patients and $25.6 \%$ of the doctors. The concordance between patient-recorded and doctor-recorded symptoms was generally low, with the highest percentage of agreeing answers for abdominal pain. The combination of a doctor's positive history of patient rectal bleeding in combination with a positive FIT showed a high PPV of $25.6 \%$ (95\% CI 12.5-38.6) for CRC and IBD. Rectal bleeding was the only symptom reported by both patients and doctors that was associated to CRC/IBD.
Unexpectedly, almost half of the patients recorded rectal bleeding. To our knowledge, only one previous study has reported on patients' symptoms (doctor-reported) when FITs were requested in primary care [23]. In this Danish study, that presents no information about rectal bleeding and that did not include patients eligible for urgent referral, the most frequent symptoms were abdominal pain (53.9\%) and change in bowel habits (45.6\%). These figures are in line with the present study.

Not surprisingly, the percentage of agreeing positive answers from patients and doctors increased with the severity of symptoms recorded by patients. However, even when "severe discomfort" or worse was recorded by patients, in $15 \%$ of cases doctors had not recorded abdominal pain, and in $11 \%$ of cases they had not recorded diarrhoea. A low concordance between patient-reported and doctor-recorded symptoms has also been seen in studies concerning other conditions [24, 25]. The percentage of agreeing positive answers to questions about urgency and incomplete evacuation of faeces was low, and a higher proportion of the doctors answered these questions with "unknown". It is probable that doctors considered these symptoms to be less important.

There was a substantial discrepancy between numbers of patients and doctors that recorded rectal bleeding, and the percentage of agreeing positive answers was as low as $56.8 \%$. This may have several explanations: other symptoms may have dominated, the bleeding may have been interpreted as caused by unimportant haemorrhoids, patients may be less willing to talk about rectal issues than other symptoms, and doctors may have forgotten to ask about bleeding. A former study with patients diagnosed with rectal cancer reported that over $50 \%$ initially attributed their symptoms to haemorrhoids and thought that the symptoms were not serious [26]. This indicates that patients may hesitate to mention rectal bleeding in the consultation.

In spite of the difference in recording of rectal bleeding, this was the only symptom that was significantly associated with the diagnoses of CRC or IBD, both when recorded by patients and by doctors. This relationship has also been found in previous studies [27]. As it seems important not to miss rectal bleeding, further research on how to improve communication between patients and doctors on this subject could be useful.

However, over $50 \%$ of the cases with recorded rectal bleeding had negative FITs, both when the bleeding was recorded by the doctor and by the patient, and only one patient that recorded rectal bleeding and had a negative FIT had CRC. (In this case it was also unlikely that the bleeding was caused by the CRC, as the patient reported blood on the toilet paper and had a right-sided tumour.) Adding FIT results to the history of rectal bleeding increased the PPV for CRC and IBD substantially and also 
gave a high NPV. Previous studies have shown that FITs may be useful in prioritising patients that had already been referred to secondary care [28-34]. A recently published study shows similar results when FITs were requested in primary care [35]. Guidelines on suspected CRC instruct primary care doctors to refer patients with unexplained rectal bleeding. It can be challenging for primary care doctors to rule out CRC in patients with rectal bleeding and findings of haemorrhoids. In these cases, a negative FIT combined with an anorectal investigation could help rule out CRC in a primary care setting. Interestingly, FITs have already been used in these situations by doctors as a triage tests in primary care in Sweden [36].

Irrespective of blood being recorded to occur on the paper only or in the toilet, the PPVs and NPVs for CRC and IBD were similar - thus it seems to be of less importance to distinguish between different locations of blood.

Reports of a change in bowel habits, as an isolated symptom, was not associated with significant colorectal disease in this study. Instead diarrhoea may be more connected to significant bowel disease. Constipation was not associated with significant bowel disease, which is in line with earlier findings [37].

Our study has several limitations. Firstly, the study starts from the consultation when the doctor requested a FIT and we cannot rule out that some patients prior to the inclusion had consulted a doctor for gastrointestinal symptoms. Also, patients may have been referred for endoscopy without previous testing. However, the patients included are those where doctors presumably were in need of a diagnostic aid. Secondly, patients were asked to record symptoms during a specified period, while doctors were asked to record symptoms presented at the consultation. This may to some extent have effected the percentage of agreeing positive answers for patientreported and doctor-reported symptoms in our study. Thirdly, not all patients underwent bowel imaging. However, due to the two-year observation period it is unlikely that any cases of CRC or IBD were missed. Also, of the eligible patients, $26 \%$ did not consent to participate or return the questionnaire and possibly the nonparticipants could have differed from those in the participating group. However, age and sex distribution were similar in the two groups.

The FIT used in this study was qualitative with a cutoff of $25-50 \mu \mathrm{g}$ haemoglobin/g $(\mathrm{Hb} / \mathrm{g})$ faeces. Previous studies on already referred patients have shown that a qualitative POC FIT with a cut-off of $<6 \mu \mathrm{g} \mathrm{Hb/g}$ and quantitative FITs with cut-offs from detectable blood to $15 \mu \mathrm{g} \mathrm{Hb} / \mathrm{g}$ faeces could with reasonable safety rule out significant colorectal disease [28, 30, 32, 33]. Thus, considerably lower cut-off values were used in these studies.
In England, the NICE diagnostic guidance with recommendations on referral for suspected CRC in primary care recommends quantitative FITs with cut-offs of $10 \mu \mathrm{g} \mathrm{Hb} / \mathrm{g}$ for patients with low risk symptoms [13]. A Danish study on patients where FITs were requested by doctors before referral used a quantitative FIT with a cut-off of $10 \mu \mathrm{g} \mathrm{Hb} / \mathrm{g}$ faeces and showed a PPV of $11.5 \%$ for CRC and IBD in patients with non-alarm symptoms [23]. As the clinical observation time after a negative FIT was only 3 months the NPV in that study seems uncertain. For the use of FITs as rule-out tests in primary care, it is important to find the optimal cut-off level so as to prevent unnecessary referrals and avoid missing cases of significant colorectal disease, especially CRC. Further studies are necessary to determine this level. The combination of a FIT with a haemoglobin value could be useful [12].

\section{Conclusion}

Doctors should be aware that, during consultations, they do not record all symptoms experienced by patients. FITs requested by doctors in primary care when found positive may potentially be of help in prioritising referrals, also when patients present with the alarm symptoms of rectal bleeding or change in bowel habits.

\section{Supplementary information}

Supplementary information accompanies this paper at https://doi.org/10. 1186/s12875-020-01194-X.

Additional file 1. Patients information

Additional file 2. Questions about gastrointestinal symptoms

Additional file 3. Questions to the doctor who has requested a Faecal Immunochemical Test (FIT) for this patient

\section{Abbreviations}

CRC: Colorectal cancer; CRD: Colorectal disease; FIT: Faecal immunochemical test; GSRS-IBS: Gastrointestinal Symptom Rating Scale for irritable bowel syndrome; HGD: High-grade dysplasia; IBD: Inflammatory bowel disease; LGD: Low-grade dysplasia; OR: Odds ratio; NPV: Negative predictive value; POC: Point of care; PPV: Positive predictive value

\section{Acknowledgements}

We would like to thank the patients, nurses and doctors who participated in this study.

\section{Authors' contributions}

$\mathrm{CH}$ conceived the study. $\mathrm{CH}, \mathrm{PK}, \mathrm{JR}$ and ML designed the study. $\mathrm{CH}$ collected the data, led the data analysis and wrote the manuscript. PK, JR and ML analysed the data and critically reviewed and revised the manuscript. All authors read and approved of the final manuscript.

\section{Funding}

This work was supported with grants by Region Jämtland Härjedalen (JLL-369741, JLL-376341, JLL-458771), Northern County Councils (Visare Norr) VisareNorr467541, VisareNorr557151), Regional Cancer Centre North, Swedish society of Medicine (SLS-324961, SLS-412311), and Lions Cancer Research Foundation Umeå University (AMP14-765, LP15-2092). The funding sources had no role in the study design, data collection, analysis, data interpretation, manuscript review or decision to publish. Open access funding provided by Umea University. 


\section{Availability of data and materials}

The datasets used and analysed during the current study are available from the corresponding author on reasonable request.

\section{Ethics approval and consent to participate}

Ethical approval was obtained from the Regional Ethical Review Board Umeå (Regionala etikprövningsnämnden I Umeå), Umeå University (reference number 2012-391-31 M). Patients gave their verbal informed consent to participate in the study as described in the Methods section and this was approved by the ethics committee.

\section{Consent for publication}

Not applicable.

\section{Competing interests}

The authors declare that they have no competing interests.

\section{Author details}

'Department of Public Health and Clinical Medicine, Unit of Research, Education and Development - Östersund, Östersund Hospital, Umeå University, Umeå, Sweden. ${ }^{2}$ Department of Public Health and Clinical Medicine, Division of Medicine, Umeå University, Umeå, Sweden.

${ }^{3}$ Department of Surgical and Perioperative Sciences, Umeå University, Umeå, Sweden.

Received: 16 January 2020 Accepted: 15 June 2020

Published online: 01 July 2020

\section{References}

1. Global Cancer Observatory. Cancer Today. https://gco.iarc.fr/today/home Accessed 29 May 2020

2. Kolligs FT. Diagnostics and epidemiology of colorectal Cancer. Visc Med 2016:32:158-64

3. Torring ML, Frydenberg M, Hansen RP, Olesen F, Vedsted P. Evidence of increasing mortality with longer diagnostic intervals for five common cancers: a cohort study in primary care. Eur J Ca. 2013;49:2187-98.

4. NICE guidelines. Suspected cancer: recognition and referral. 2015, updated July 2017. https://www.nice.org.uk/guidance/ng12 Accessed 29 May 2020.

5. Regionala cancercentrum i samverkan. Standardiserat vårdförlopp tjock- och ändtarmscancer samt analcancer. 2016. http://www.cancercentrum.se/ samverkan/cancerdiagnoser/tjocktarm-andtarm-och-anal/ Accessed 29 May 2020.

6. Sundhedsstyrelsen. Pakkeforløb for kræft i tyk- og endetarm. 2016. https:// www.sst.dk/da/viden/kraeft/kraeftpakker/ Accessed 29 May 2020.

7. Rasmussen S, Larsen PV, Sondergaard J, Elnegaard S, Svendsen RP, Jarbol DE. Specific and non-specific symptoms of colorectal cancer and contact to general practice. Fam Pract. 2015;32:387-94.

8. Talley NJ, Jones M. Self-reported rectal bleeding in a United States community: prevalence, risk factors, and health care seeking. Am J Gastroenterol. 1998;93:2179-83.

9. Jones R, Charlton J, Latinovic R, Gulliford MC. Alarm symptoms and identification of non-cancer diagnoses in primary care: cohort study. BMJ. 2009:339:b3094

10. Bjerregaard NC, Tottrup A, Sorensen HT, Laurberg S. Diagnostic value of selfreported symptoms in Danish outpatients referred with symptoms consistent with colorectal cancer. Color Dis. 2007;9:443-51.

11. Hamilton W, Lancashire R, Sharp D, Peters TJ, Cheng K, Marshall T. The risk of colorectal cancer with symptoms at different ages and between the sexes: a case-control study. BMC Med. 2009:7:17.

12. Högberg C, Karling P, Rutegård J, Lilja M. Diagnosing colorectal cancer and inflammatory bowel disease in primary care: the usefulness of tests for faecal haemoglobin, faecal calprotectin, anaemia and iron deficiency. A prospective study. Scand J Gastroenterol. 2017;52:69-75.

13. NICE Guidance. Quantitative faecal immunochemical tests to guide referral for colorectal cancer in primary care. 2017. https://www.nice.org.uk/ guidance/dg30 Accessed 29 May 2020.

14. Högberg C, Karling P, Rutegård J, Lilja M, Ljung T. Immunochemical faecal occult blood tests in primary care and the risk of delay in the diagnosis of colorectal cancer. Scand J Prim Health Care. 2013;31:209-14.
15. Fraser CG. Faecal immunochemical tests (FIT) in the assessment of patients presenting with lower bowel symptoms: concepts and challenges. Surgeon 2018;16:302-8

16. Westwood M, Lang S, Armstrong N, van Turenhout S, Cubiella J, Stirk L, et al. Faecal immunochemical tests (FIT) can help to rule out colorectal cancer in patients presenting in primary care with lower abdominal symptoms: a systematic review conducted to inform new NICE DG30 diagnostic guidance. BMC Med. 2017;15:189.

17. Steele RJ, Fraser CG. Faecal immunochemical tests (FIT) for haemoglobin for timely assessment of patients with symptoms of colorectal disease. In: Olsson L, editor. Timely diagnosis of colorectal Cancer. Cham: Springer; 2018

18. Godber IM, Benton SC, Fraser CG. Setting up a service for a faecal immunochemical test for haemoglobin (FIT): a review of considerations, challenges and constraints. J Clin Pathol. 2018;71:1041-5.

19. STARD 2015: An updated list of essential items for reporting diagnostic accuracy studies. 2015. http://www.equator-network.org/reportingguidelines/stard/ Accessed 29 May 2020.

20. Wiklund IK, Fullerton S, Hawkey CJ, Jones RH, Longstreth GF, Mayer EA, et al. An irritable bowel syndrome-specific symptom questionnaire: development and validation. Scand J Gastroenterol. 2003;38:947-54.

21. Dimenäs E, Glise H, Hallerbäck B, Hernqvist H, Svedlund J, Wiklund I. Quality of life in patients with upper gastrointestinal symptoms: an improved evaluation of treatment regimens? Scand J Gastroenterol. 1993;28:681-7.

22. Oy Medix Biochemica Ab. www.medixbiochemica.com Accessed 29 May 2020

23. Juul JS, Hornung N, Andersen B, Laurberg S, Olesen F, Vedsted P. The value of using the faecal immunochemical test in general practice on patients presenting with non-alarm symptoms of colorectal cancer. Br J Cancer. 2018;119:471-9.

24. Miravitlles M, Ferrer J, Baró E, Lleonart M, Galera J. Differences between physician and patient in the perception of symptoms and their severity in COPD. Respir Med. 2013;107:1977-85

25. Strömgren AS, Groenvold M, Pedersen L, Olsen AK, Spile M, Sjøgren P. Does the medical record cover the symptoms experienced by cancer patients receiving palliative care? A comparison of the record and patient self-rating. J Pain Symptom Manag. 2001;21:189-96.

26. Ristvedt SL, Birnbaum EH, Dietz DW, Fleshman JW, Kodner IJ, Read TE. Delayed treatment for rectal cancer. Dis Colon Rectum. 2005;48:1736-41.

27. Astin M, Griffin T, Neal RD, Rose P, Hamilton W. The diagnostic value of symptoms for colorectal cancer in primary care: a systematic review. $\mathrm{Br}$ J Gen Pract. 2011;61:e231-43.

28. McDonald PJ, Digby J, Innes C, Strachan JA, Cary FA, Steele RJ, et al. Low faecal haemoglobin concentration potentially rules out significant colorectal disease. Color Dis. 2013:11:329-31.

29. Cubiella J, Salve M, Diaz-Ondina M, Vega P, Alves MT, Iglesias F, et al. Diagnostic accuracy of the faecal immunochemical test for colorectal cancer in symptomatic patients: comparison with NICE and SIGN referral criteria. Color Dis. 2014;16:0273-82.

30. Rodriguez-Alonso L, Rodriguez-Moranta F, Ruiz-Cerulla A, Lobaton T, Arajol C, Binefa $G$, et al. An urgent referral strategy for symptomatic patients with suspected colorectal cancer based on a quantitative immunochemical faecal occult blood test. Dig Liver Dis. 2015:47:797-804.

31. Godber IM, Todd LM, Fraser CG, MacDonald LR, Younes HB. Use of a faecal immunochemical test for haemoglobin can aid in the investigation of patients with lower abdominal symptoms. Clin Chem Lab Med. 2016;54: 595-602.

32. Mowat C, Digby J, Strachan JA, Wilson R, Carey FA, Fraser CG, et al. Faecal haemoglobin and faecal calprotectin as indicators of bowel disease in patients presenting to primary care with bowel symptoms. Gut. 2016;65: 1463-9.

33. Elias SG, Kok L, de Wit NJ, Witteman BJ, Goedhard JG, Romberg-Camps MJ, et al. Is there an added value of faecal calprotectin and haemoglobin in the diagnostic work-up for primary care patients suspected of significant colorectal disease? A cross-sectional diagnostic study. BMC Med. 2016;14:141.

34. Widlak MM, Thomas CL, Thomas MG, Tomkins C, Smith S, O'Connell N, et al Diagnostic accuracy of faecal biomarkers in detecting colorectal cancer and adenoma in symptomatic patients. Aliment Pharmacol Ther. 2017:45:354-63.

35. Mowat C, Digby J, Strachan JA, McCann R, Hall C, Heather D, et al. Impact of introducing a faecal immunochemical test (FIT) for haemoglobin into 
primary care on the outcome of patients with new bowel symptoms: a prospective cohort study. BMJ Open Gastro. 2019;6:e000293.

36. Högberg C, Samuelsson E, Lilja M, Fhärm E. Could it be colorectal cancer? General practitioners' use of the faecal occult blood test and decision making - a qualitative study. BMC Fam Pract. 2015;16:153.

37. Power AM, Talley NJ, Ford AC. Association between constipation and colorectal cancer: systematic review and meta-analysis of observational studies. Am J Gastroenterol. 2013;108:894-903.

\section{Publisher's Note}

Springer Nature remains neutral with regard to jurisdictional claims in published maps and institutional affiliations.

Ready to submit your research? Choose BMC and benefit from:

- fast, convenient online submission

- thorough peer review by experienced researchers in your field

- rapid publication on acceptance

- support for research data, including large and complex data types

- gold Open Access which fosters wider collaboration and increased citations

- maximum visibility for your research: over $100 \mathrm{M}$ website views per year

At $\mathrm{BMC}$, research is always in progress.

Learn more biomedcentral.com/submissions 